Background Predicting the impact on services is essential for managing large public events.

Objectives To measure the impact of the 2012 Olympics on service use in London

Methods Data were gathered from London sexual health services in London for July-September 2012 relating to contraception, sexual assault, sex worker services and telephone sexual health advice

Results Emergency contraception prescriptions rose by $20 \%$ (from 1086 to 1353) over the Olympic and post-Olympic period as compared to the previous month. In the Brook London contraception clinics there was a 9\% rise (from 1209 to 1328) in all attendance over the Olympic period as compared with 2011. In the three main sexual assault services, $1-7 \%$ of reported incidents were in clients who were visiting the Olympics. In a survey of 102 sex workers, 59\% (59/102) reported fewer clients and $46 \%$ $(46 / 102)$ reported more police interference and brothel closures. Sixteen (16\%) were new sex workers and 7\% (7/102) came to London specifically for the Olympics. Telephone advice line calls about sexual health fell by $19 \%$ (from 741 in the previous month to 622 over the Olympics) then rose by 25\% (from 622 to 828 ) in the month after the Olympics. This increase was mainly due to calls by women with vaginal symptoms (from 112 to 184, 61\% increase) and urinary tract problems (from 150 to 223, 67\% increase).

Conclusions Contraception service use was higher and emergency contraception prescriptions increased following the Olympics. Reported use of sexual assault services, sex workers and telephone advice was low during the Olympics but there was a large rise in requests for sexual health advice afterwards. These data will prove valuable in planning sexual health service provision for cities with large-scale events in the future

\section{P3.342 SEX AND THE 2012 OLYMPICS PART 2. PROSPECTIVE STUDY OF THE IMPACT OF OLYMPIC VISITORS ON SPECIALIST STI SERVICES IN LONDON AND WEYMOUTH AND ON STIS DIAGNOSED}

doi:10.1136/sextrans-2013-051184.0795

'G Brook, ${ }^{2} \mathrm{~V}$ Hall, ${ }^{2} \mathrm{G}$ Hughes, ${ }^{2} \mathrm{~K}$ Marsh, ${ }^{3} \mathrm{~A}$ Hartley, ${ }^{4} \mathrm{R}$ Foster, ${ }^{2} \mathrm{P}$ Crook, ${ }^{5} \mathrm{~K}$ Coyne, ${ }^{6} \mathrm{C}$ Mercer, ${ }^{7} \mathrm{~J}$ Cassell. ${ }^{1}$ Central Middlesex Hospital, London, UK; ${ }^{2}$ Health Protection Agency, London, UK; ${ }^{3}$ Barts and The London Hospitals, London, UK; ${ }^{4} S t$. Marys Hospital, London, UK; ${ }^{5}$ Homerton University Hospital, London, UK; ${ }^{6}$ University College, London, UK; ' Brighton and Sussex Medical School, Brighton, UK

Background Predicting the impact on services is essential for managing large public events.

Objectives To measure the impact of the Olympics on STI services Methods Between 20 Jul-16 Sept 2012, new registrants at STI clinics in London and Weymouth were asked to complete a survey to determine if they were visitors to the Olympics from the UK and abroad. Survey responses were linked to the national specialist STI clinic activity dataset (GUMCAD)

Results Provisional data show that 24/35(69\%) clinics returned 12347 surveys. Among respondents, 11158(90\%) were local residents, 1081(9\%) non-Olympic visitors and 108(0.9\%) Olympic visitors (OV). Survey participation was $12347 / 37704(33 \%)$. Most OVs were seen in central London clinics $(52,48 \%)$ and Weymouth (21, $19 \%)$, with the majority $(66,61 \%)$ attending during the Olympics (27 Jul-12 Aug). The percentage of new registrants who were OVs reached a maximum of $9 \%$ per week in one London clinic and $21 \%$ per week in Weymouth

Among OV respondents, 37 (35\%) were non-UK residents and $59(55 \%)$ were Olympic workers. Compared with locals, OV were more likely to be male ( $74 \%$ vs $59 \%$ ), in the $15-24$ age range (44\% vs $36 \%$ ) and ethnically white ( $83 \%$ vs $68 \%$ ). There were no differences in sexual orientation but a higher prevalence of acute STIs among OVs $(12 / 108,11.1 \%)$ vs locals $(950 / 11158,8.5 \%)$ was reported. A total of 30 STIs were diagnosed among OVs including NSU (10, $9 \%)$, chlamydia $(5,5 \%)$, warts $(5,5 \%)$, herpes $(4.4 \%)$, gonorrhoea (3.3\%), molluscum $(2.2 \%)$ and scabies $(1.1 \%)$

Conclusions For the first time in the history of the Olympics, the impact of visitor attendance at sexual health clinics has been measured prospectively. OV were seen in substantial numbers only during the Games and had comparable STI rates to locals. These data will prove valuable in planning future sexual health services for cities with large-scale events

\section{P3.343 HOW WELL DO WEB PANEL SURVEYS MEASURE SENSITIVE BEHAVIOURS IN THE GENERAL POPULATION, AND CAN THEY BE IMPROVED? A COMPARISON WITH THE THIRD BRITISH NATIONAL SURVEY OF SEXUAL ATTITUDES \& LIFESTYLES (NATSAL3)}

doi:10.1136/sextrans-2013-051184.0796

'B Erens, ${ }^{2} \mathrm{~S}$ Burkill, ${ }^{2} \mathrm{~A}$ Copas, ${ }^{3} \mathrm{M}$ Couper, ${ }^{3} \mathrm{~F}$ Conrad, ${ }^{2} \mathrm{C}$ Tanton. ${ }^{1}$ London School of Hygiene \& Tropical Medicine, London, UK; '2University College London, London, UK; 3University of Michigan, Ann Arbor, MI, United States

Background Surveys play an important role in providing public health data for researchers and policy-makers. Traditional modes of survey data collection are subject to declining response rates and increasing costs. With the spread of the internet among the population, web surveys potentially provide a cost-effective alternative mode. Volunteer web panels are now widely used for market research/opinion polling, but less for academic/government research due to concerns about their representativeness. Various methods attempt to make web panels more "representative" of the population. We compared results from four UK web panels with a national probability survey.

Methods A shortened Natsal3 questionnaire was included on four web panels: two used standard demographic quotas, and two were 'modified' using variables correlated with key outcomes as additional quotas. After weighting for age and sex, comparisons were made with Natsal3 for demographic characteristics, key behaviours and attitudes, to examine whether modified quotas 'improved' the results.

Results All four web panels gave significantly different results from Natsal3 on a majority of the variables. There were more differences among men than women for all the web panels. There were more differences between the web panels and Natsal3 questions asked face-to-face (CAPI) than in self-completion format (CASI). The web panels also differed significantly from each other. One of the modified quota web panels produced estimates closer to Natsal3 than the standard quota panels, but still differed on three-fifths of the variables. Moreover, meeting the modified quotas proved difficult, and the quotas had to be relaxed in both cases.

Conclusions When measuring sensitive sexual behaviours in the UK population, volunteer web panels provided significantly different estimates than a probability CAPI/CASI survey. Adjusting web panel quotas did not lead to much improvement.

\section{P3.344 HIV AIDS SURVEY IN THE ARMED FORCES IN REPUBLIC OF DJIBOUTI}

doi:10.1136/sextrans-2013-051184.0797

A Ahmed Abdi, I Hassan Farah. Armed Forces Health Service, Djibouti, Djibouti

Introduction National prevalence of HIV/AIDS in Djibouti is estimated at 3\% based on 2002 data moreover the military are considered as at-risk group. An HIV/AIDS seroprevalence survey in 2006 was conducted over a population composed of the Armed Forces to assess the seroprevalence of HIV/AIDS among Djiboutian military forces. 